\title{
Bromocriptine - A Novel Therapy in Type-2 Diabetes
}

\author{
Poondy Gopalratnam Raman* \\ MGM Medical College, India \\ *Corresponding author: Poondy Gopalratnam Raman, MGM Medical College, India
}

Received: 酶 June 27, 2019

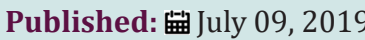

\begin{abstract}
Bromocriptine is used in treatment of diabetes mellitus. It acts by increasing dopaminergic activity in hypothalamus and lowers HbA1c by 0.6 to $0.9 \%$. It is not to be used in type 1 diabetes and DKA.
\end{abstract}

Keywords: Bromocriptine; Hypothalamus; Contra indicators; Infarction; Combination therapy; Quick release bromocriptine

\section{Introduction}

Bromocriptine mesylate is a new modality of treatment for type-2 diabetes. The drug increases dopaminergic activity in the hypothalamus. It lowers $\mathrm{HbA1c}$ by 0.6 to $0.9 \%$ compared to placebo when added to other oral anti-diabetic agents. It regulates metabolic rhythm. The drug increases insulin sensitivity [1]. There is $24 \%$ increase in insulin mediated glucose disposal. Reduces fasting and post prandial hyper insulinemia by $30-70 \%$. Body fat stores and insulin action are controlled by temporal interactions of circadian neuro-endocrine oscillations. Bromocriptine modulates neurotransmeter action in the brain and has been shown to improve glucose tolerance and insulin resistance in obesity and diabetes. Bromocriptine improves glycemic control and glucose tolerance in obese type-2 DM. Both fasting and post prandial blood glucose are reduced. This is due to enhanced maximally stimulated insulin mediated glucose disposal [2]. No change in body weight or BMI occurred with this therapy. Mechanism of Action is unclear. It resets the circadian rhythm at hypothalamic level $[3,4]$. Preclinical data suggest that decreased hypothalamic dopaminergic tone may be involved in the pathogenesis of insulin resistance. The normal circadian cycle that results in a leaner body in the summer and heavier body in winter is disrupted in humans because of abundant caloric intake year-round resulting in the absence of a lean phase. Stimulation of the hypothalamus promotes the release of several hormones that respond to the traditional shift in caloric intake and storage. Quick-release bromocriptine (D2 against), given once in the morning, stimulates the hypothalamus to release cortisol, growth hormone, and prolactin, allowing a reset of the circadian clock permanently stuck in a winter rhythm. This means there occurs resetting of abnormally elevated hypothalamic drive for increased plasma glucose, triglyceride and free fatty acid levels in fasting and postprandial states in insulin-resistant patients. Other mechanisms, including $\alpha-1$ antagonist, $\alpha-2$ agonist, and serotonin and prolactin modulator, may also help to explain bromocriptine's glucose-lowering effects (Table 1). Bromocriptine quick release (Cycloset) was added on to various antidiabetic agents and studied for 52 weeks safety trial and was found to be useful as add on therapy [4].

Table 1: 24 weeks trial (245) subjects with type-2 diabetes (summary) [3].

\begin{tabular}{|c|c|c|}
\hline Parameters & Cycloset with SU & Placebo with SU \\
\hline 1. HbA1C initial & $9.3 \%$ & $9.4 \%$ \\
\hline $\begin{array}{c}\text { HbA1C after 24 weeks } \\
\text { reduction }\end{array}$ & $-0.4 \%$ & $-0.3 \%$ \\
\hline 2. FBS & $220 \mathrm{mg} / \mathrm{dL}$ & $226 \mathrm{mg} / \mathrm{dL}$ \\
\hline $\begin{array}{c}\text { After 24 weeks of } \\
\text { therapy }\end{array}$ & $23 \mathrm{mg} / \mathrm{dL}$ (reduction) & $3 \mathrm{mg} / \mathrm{dL}$ (reduction) \\
\hline $\begin{array}{c}\text { 3. Body weight after } \\
\text { 24 weeks therapy }\end{array}$ & $+0.9 \mathrm{~kg}$ & $+0.5 \mathrm{~kg}$ \\
\hline
\end{tabular}

\section{Dosage}

To be given within 2 hours are waking with food. Starting dose is $0.8 \mathrm{mg}$. Recommended dose is 1.6 to $4.8 \mathrm{mg}$.

\section{Side Effects}

Can cause nausea. Taking with food minimise nausea. Can produce hypotension, somnolence, headache, fatigue, vomiting, diarrhea, constipation and dizziness. Loss of consciousness during migraine may reflect dopamine receptor hypersensitivity $[5,6]$. 


\section{Contraindications $[5,6]$}

a. Hypersensitivity to Ergot

b. Syncope is potentiated

c. Inhibits lactation, hence, not to be given in lactating mothers

d. Type-I DM or diabetic ketoacidosis

e. Not to be given during pregnancy

f. Syncopal migraine

\section{Interaction [5,6]}

Interact with dopamine receptor antagonist, clozapine, olanzapine and reduces the effectiveness. Increases serum levels of Salycilates, Sulfonamide, Chloramphenicol and Probenecid due to its high protein binding character. Avoid using concomitantly with other Dopamine antagonist such as neuroleptics. They diminish the effectiveness of Bromocriptine.

\section{Storage}

Store at $25^{\circ} \mathrm{C}$ and protect from light and moisture.

\section{Conclusion}

Bromocriptine mesylate is indicated as an adjunct to diet and exercise to improve glycemic control in adults with type-2 diabetes

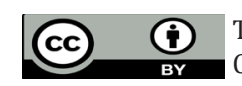

This work is licensed under Creative Commons Attribution 4.0 License

To Submit Your Article Click Here:

Submit Article

DOI: $10.32474 / A D 0.2019 .02 .000134$

mellitus. It may be used as monotherapy or as adjunctive therapy to metformin/sulfonylurea. It should not be used to treat type-1 diabetes or diabetic ketoacidosis.

\section{References}

1. Ashraf Aminorroaya, Mohsen Janghorbani, Majid Ramezani, Sassan Haghighi, Massoud Amini (2004) Does Bromocriptine Improve Glycemic Control of Obese Type-2 Diabetics?. Hormone Research 62(2): 55-59.

2. Pijl H, Edo AM (2002) Modulation of monoaminergic neural circuits: Potential for the treatment of type 2 diabetes mellitus. Treatments in Endocrinology 1(2):71-78.

3. Cincotta AH, Meier AH, Cincotta Jr M (1999) Bromocriptine improves glycaemic control and serum lipid profile in obese Type 2 diabetic subjects: A new approach in the treatment of diabetes. Expert Opinion on Investigational Drugs 8(10): 1683-1707.

4. Gaziano JM (2007) Quick-release bromocriptine has favorable cardiovascular safety profile. Proceedings of the $67^{\text {th }}$ Annual Scientific Sessions of the American Diabetes Association, USA.

5. Bromocriptine mesylate approved for treatment of type 2 diabetes (2009) Endocrine today.

6. Mahajan R (2009) Bromocriptine mesylate: FDA-approved novel treatment for type-2 diabetes. Indian J Pharmacol 41(4):197-198.

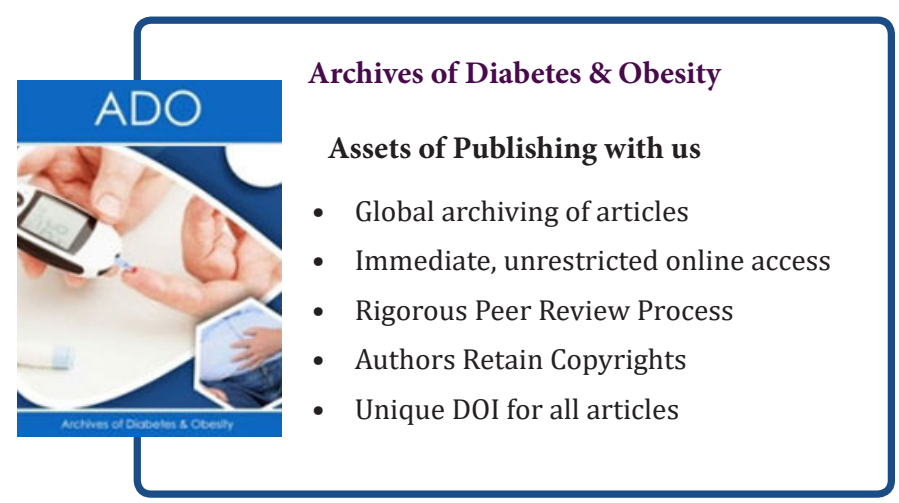

